\title{
PROBLEMAS DE SUMAR Y RESTAR EN LOS CUADERNOS RUBIO (ESPAÑA)
}

\section{Aditive and sustractive problems in Rubio notebooks (Spain)}

Dolores Carrillo Gallego

Correo-e: carrillo@um.es

José Francisco Castejón Mochón

Correo-e: jfcaste@um.es.

Pilar Olivares Carrillo

Universidad de Murcia

Correo-e:pilar.olivares@um.es

Recepción: 13 de junio de 2020. Envío a informantes: 2I de junio de 2020 Aceptación definitiva: 2 de septiembre de 2020

Resumen: Los cuadernos Rubio de aritmética han sido ampliamente utilizados en España para el aprendizaje de las operaciones aritméticas básicas desde su aparición en 1959. En el trabajo se han identificado seis épocas en la edición de estos cuadernos y se estudian los problemas de sumar y restar que proponen; para ello, se utilizan las categorías formuladas por G. Vergnaud para el campo conceptual de las estructuras aditivas. Se analizan cuadernos de problemas de la edición de 1978 (época 2), tanto los problemas verbales como los gráficos, constatando que son de los tres primeros tipos, entre los seis formulados por Vergnaud. Se estudia la evolución de estos cuadernos hasta los que se comercializan actualmente: hay continuidad en los problemas propuestos y los cambios, aparte de los producidos para adaptarlos al cambio de moneda al euro, afectan al diseño, no al contenido.

Palabras clave: cuadernos Rubio; problemas de suma y resta; situaciones aditivas; Gérard Vergnaud; Educación Primaria.

AвSTRACT: Rubio arithmetic notebooks have been widely used in Spain for learning basic arithmetic operations since their appearance in 1959. In this work, six periods have been identified in the editions of these notebooks and the problems of adding and subtracting that they propose are studied. To this end, the categories 
formulated by G. Vergnaud for the conceptual field of additive structures are used. Problem notebooks from the 1978 edition (epoch 2) are analysed, both verbal and graphical problems, noting that they are of the first three types, among the six formulated by Vergnaud. The evolution of these notebooks is studied up to current marketed editions: there is continuity in the problems proposed and the changes, apart from those modified to adapt to euro currency, affect the design, not the content.

KEY WORDS: Rubio notebooks; addition and subtraction problems; additive situations; Gérard Vergnaud; Primary Education.

\section{Aportaciones de los cuadernos escolares a la investigación en Historia de la Educación Matemática}

$\mathrm{E}$

N LA INVESTIgAción en Historia de la Educación y, en particular, en Historia de la Educación Matemática (HEM), los cuadernos escolares constituyen un tipo de fuente que se está poniendo en valor pues son un índice del trabajo realizado por el alumnado en su aprendizaje. La utilización de los cuadernos se relaciona con las corrientes historiográficas que ponen el acento en

el reconocimiento y auge de la microhistoria, la vuelta del sujeto como tema histórico relevante, las llamadas de atención sobre la necesidad de entrar en esa caja negra de la historia de la educación que son las aulas y lo que ha sucedido en ellas, y el creciente interés por las escrituras ordinarias, populares e infantiles ${ }^{1}$.

Los trabajos pioneros en el uso de los cuadernos escolares en el ámbito de la Historia de la Educación aparecieron en los años 90 del pasado siglo, con las aportaciones de Anne Marie Chartier, Silvina Gvirtz y Jean Hebrard; desde entonces, además de comunicaciones en congresos y trabajos publicados en revistas especializadas, se han realizado reuniones específicas como el Simposio que se celebró, en 2007, en la Universidad de Macerata²; el curso, en 2009, dentro del VIII Seminário Nacional de História da Matemática ${ }^{3}$, y el Seminario Temático «Cadernos de alunos e professores e a história da educação matemática, I890-

Viñao Frago, A.; Chiosso, G. y Gibelli, A.: «School Exercise Books. A complex source for a history of the approach to schooling and education in the $19^{\text {th }}$ and $20^{\text {th }}$ centuries», History of Education E Children's Literature, IV, (20II), pp. 447-466, cita en p. 447.

2 Las contribuciones a este Simposio están publicadas en Meda, J.; Montino, D. y Sani, R.: School Exercise Books. A complex source for a history of the approach to schooling ans education in the $19^{\text {th }}$ and $2 \mathrm{O}^{\text {th }}$ centuries, Florence (Italia), Polistampa, 2010.

3 Silva, M. C. L. y Valente, W. R.: Na oficina do historiador da educação matemática: cadernos de alunos como fontes de pesquisa, Mendes, I. A. y Chaquiam, M. (orgs.). Belém, SBHMt, 2009 (Coleção História da Matemática para Professores, I9). 
I990", celebrado en la Universidad Federal de Pelotas (Brasil) en el año 20I7 ${ }^{4}$. Algunos trabajos de HEM que han utilizado los cuadernos escolares, además de los publicados en HISTEMAT en 2017, son los de Carrillo Gallego y Sánchez Jiménez, en 2017; Bertini, en 2019, y De Godoi y Da Costa en $2020^{5}$.

Unos trabajos básicos sobre la investigación en Historia de la Educación utilizando cuadernos escolares son los de Viñao $(2006)^{6}$ y su ampliación, en el caso de España, en $2013^{7}$; en ellos, además de documentar los trabajos realizados hasta ese momento, y señalar la variedad de enfoques de los mismos, presenta una caracterización amplia del concepto cuaderno escolar para incluir las diversas formas que pueden tener los trabajos de los alumnos. A partir de los diferentes usos de los cuadernos en la investigación en Historia de la Educación, identifica dieciséis tipos de cuadernos escolares. Una de las categorías son los «producidos por casas editoriales» que aparecieron como «un producto editorial que facilitaba la tarea del maestro o profesor» ${ }^{8}$. En el caso de los cuadernos de este tipo, dedicados al cálculo, se trataba de

proporcionar al niño una serie graduada de ejercicios con vista a la adquisición de un rápido y seguro manejo de los mecanismos operatorios que al menos han de economizar el trabajo de copiar los datos que se le dan ya ordenados, quedando a cargo del alumno únicamente el hallazgo de los resultados. El Maestro, por otra parte, encuentra graduados los ejercicios y no tiene que molestarse en proponerlos?

Este tipo de cuadernos, que tienen características que los acercan a los libros de texto, ha sido poco utilizado en investigaciones sobre Historia de la Educación. Este trabajo utiliza cuadernos de este tipo, los editados por Ediciones Técnicas Rubio a partir de 1978 y dedicados a los problemas de sumar y restar. Dentro de la categoría "producidos por casas editoriales», se pueden incluir también los «libros de fichas» que, en las últimas décadas, se comercializan asociados a los libros de texto.

4 Este Seminario temático dio lugar a un dosier publicado en la revista, especializada en HEM, HISTEMAT, en 2017.

5 Carrillo-Gallego, D. y Sánchez-Jiménez, E.: «El «cálculo vivo» en un cuaderno freinetiano», Histemat, v. 3-3 (2017), pp. 40-54; BERTINI, L. F.: «Problemas de Aritmética: participação na marcha de ensino e na relação com a vida prática (cadernos de alunos franceses - 1890 a 1936)», Bolema, n. 64 (2019); De GodoI, A. J. y DA CosTA, D. A.: «Saberes em transformação na matemática moderna: os cadernos escolares de alunos do ensino primário (I960-1969)", Histemat, v. 6-I (2020), pp. 98-II6.

6 ViñaO Frago, A. «Los cuadernos escolares como fuente histórica: aspectos metodológicos e historiográficos». Annali di Storia dell'Educazione e delle Istituzioni Scholastiche, n. I3, (2006), p. 17-35.

Viñao-Frago, A.: «Balance de la investigación sobre cuadernos escolares en España», en Meda, J. y BAdANelli, A. (eds.): La historia de la cultura escolar en Italia y España: balance y perspectivas, Macerata, Edizioni Università di Macerata (EUM), 2013, pp. 63-82.

8 VIÑaO-Frago, A. et al.: «School Exercise Books...», op. cit., 20II, p. 45I.

9 Ortega-Ucedo, J. J.: «Cuadernos de trabajo: tipos, condiciones y empleo», Vida Escolar, 5I-52 (I963), pp. 32-36, cita en p. 35. 


\section{Sobre la metodología}

El objetivo del trabajo es estudiar los tipos de situaciones de sumar y restar que aparecen en los cuadernos de problemas Rubio, editados a partir de I978; para ello se utiliza la tipología de situaciones aditivas identificadas por Gerard Vergnaud dentro del campo conceptual de las estructuras aditivas ${ }^{10}$.

El trabajo utiliza el método histórico y se ha realizado a partir del fondo de cuadernos Rubio existente en el Centro de Estudios sobre la Memoria Educativa de la Universidad de Murcia (CEME). Se hace referencia a la creación y evolución de la empresa editora de los cuadernos, dedicada en exclusiva a los mismos. En el trabajo se describen los cuadernos de aritmética y se identifican épocas en su edición. Se han analizado los problemas de los cuadernos 7, 8 y 9 y las situaciones de suma y resta de los cuadernos is y 19.

En los problemas estudiados se han considerado las situaciones de sumar y restar que se resuelven con una operación (situaciones de una etapa). Su análisis se ha realizado con las categorías formuladas por G. Vergnaud para el campo conceptual de las estructuras aditivas, se ha identificado el tipo de cada situación, la posición de la incógnita y el significado de los números que intervienen. El estudio se ha realizado con los cuadernos de la época 2, en la que hay cuadernos específicos dedicados a problemas; a continuación, se han estudiado las variaciones en la redacción de los problemas propuestos a lo largo de las épocas identificadas, así como los posibles cambios en la tipología de los mismos. La cuarta parte de los problemas estudiados están planteados con ayuda de representaciones gráficas; se ha dedicado un apartado a las características de estos problemas y a la evolución de las ilustraciones.

\section{El Centro de Estudios sobre la Memoria Educativa de la Universidad de Murcia (CEME) y su fondo de cuadernos escolares}

En el año 2009 se creó en la Universidad de Murcia el Centro de Estudios sobre la Memoria Educativa (CEME), con el objetivo de «fomentar la salvaguarda, el estudio y la difusión de la memoria y el patrimonio histórico-educativo de las instituciones educativas de la Región de Murcia» ${ }^{11}$. Tiene su origen en los grupos de investigación liderados por los profesores Antonio Viñao y Pedro Luis Moreno, que han sido los dos primeros directores del mismo, y en personas, pertenecientes a diversos departamentos de la Facultad de Educación, que han realizado

Io Vergnaud, G. : «La théorie des champs conceptuels», Recherches en Didactique des Mathématiques, IO, 2-3 (I99I), pp. I33-I70. Vergnaud, G.: El niño, las matemáticas y la realidad. Problemas de la enseñanza de las matemáticas en la escuela primaria, México, Trillas, 2016.

" CEME. Centro de Estudios sobre la Memoria Educativa. Universidad de Murcia. www. um.es/web/ceme (consultado el I/08/2020). 
sus tesis doctorales bajo la dirección de dichos profesores ${ }^{12}$. Posteriormente se han ido incorporando otras personas interesadas en los objetivos del CEME.

Tanto la temática de los grupos de investigación como la de las tesis doctorales estaba relacionada con la historia de las disciplinas escolares y la cultura material e inmaterial de las instituciones educativas, lo que llevó al acopio y estudio de objetos y documentos que se han integrado en los fondos del CEME. Las actividades de carácter científico son una de las tareas prioritarias del $\mathrm{CEME}^{13}$ que se benefician de la existencia en el mismo de fondos de distinto tipo (libros de texto, material didáctico-científico, catálogos de material escolar, tarjetas postales, fotografías, documentos relacionados con las instituciones educativas...) y, en particular, existe un fondo de cuadernos escolares. Estos fondos se van alimentando con donaciones de distinta procedencia y, además de estar a disposición de investigadores, como corresponde a un Centro de Estudios, se han difundido por medio de exposiciones, como la que se realizó en 2017 sobre «Los cuadernos escolares: entre el texto y la imagen», para la cual se elaboró un catálogo de acompañamiento ${ }^{14}$.

En el fondo de cuadernos escolares hay, actualmente, más de 1500 cuadernos, de los cuales ir85 estaban catalogados en abril de 2020. Se caracteriza por la heterogeneidad de los cuadernos, por su diversa procedencia, de «casas particulares, trasteros, derribos, fondos de librerías que contaban en la trastienda con existencias antiguas que no se habían vendido, y otras circunstancias similares» ${ }^{15}$, por lo que en él están representados estudiantes de niveles medios. Los cuadernos Rubio utilizados en este trabajo provienen de este fondo. En la actualidad, hay en él 176 cuadernos Rubio de aritmética, no todos diferentes. Además, algunos no han sido utilizados, otros tienen el nombre del alumno o del maestro al que pertenecieron y los hay que se han utilizado sin que figure por quién. De algunos de los usuarios identificados, el CEME posee cuadernos de otros tipos, que pueden servir de comparación.

I2 Una descripción del CEME, su gestación, objetivos y actividad, así como su incidencia en la investigación en HEM, pueden verse en Carrillo-Gallego, D.; Moreno-Martínez, P. L. y SÁnchez-Jiménez, E.: «El Centro de Estudios sobre la Memoria Educativa (CEME) de la Universidad de Murcia y la investigación en Historia de la Educación Matemática», Historia y Memoria de la Educación, n. II (2020), pp. 615-646.

${ }_{13}$ Ibid., pp. 618-619.

14 Carrillo-Gallego, D.; López-Martínez, J. D.; Martínez Ruiz-Funes, M. J.; SánchezIbÁÑ̃z, R.; SÁnchez-Jiménez, E. y Viñao-Frago, A.: Los cuadernos escolares: entre el texto y la imagen, Murcia, Editum, 2017.

is Viñao-Frago, A. y Martínez Ruiz-Funes, M. J.: «Los cuadernos escolares y el arte de enseñar: el fondo del Centro de Estudios sobre la Memoria Educativa (CEME) de la Universidad de Murcia», en Celada Perandones, P. (ed.): Arte y oficio de enseñar. Dos siglos de perspectiva histórica, El Burgo de Osma, Sociedad Española de Historia de la Educación, Universidad de Valladolid, Centro Internacional de la Cultura Escolar, 20II, pp. 245-254 (vol. I). 


\section{Los Cuadernos Rubio}

La historia de cuadernos Rubio va ligada a la vocación del empleado de banca Ramón Rubio (1924-200I), procedente de Geldo (Castellón), que descubrió que su verdadero interés se encontraba en el gusto por enseñar a los demás. Por las mañanas era empleado de la sucursal en Valencia del Banco de Aragón, pero decidió ocupar sus tardes con su verdadera pasión, enseñar. Así, a los 25 años creó la Academia Rubio, en Valencia, por la que pasaron más de 3.500 alumnos, sobre todo opositores que deseaban optar a un puesto de contable en la banca o en una empresa ${ }^{16}$.

Fue precisamente en esta academia donde se originan los primeros Cuadernos Rubio. Para ahorrarse el tiempo que dedicaba cada día a escribir los ejercicios en la pizarra, creó unas fichas que fueron el germen de los cuadernos ${ }^{17} \mathrm{y}$, más adelante, elaboró también fichas de caligrafía. Estas fichas se reorganizaron y se presentaron en forma de cuadernillos. Surgían así, en 1956, Ediciones Técnicas Rubio y los famosos cuadernillos Rubio, que, en sus comienzos, el propio Ramón imprimiría en su casa de forma completamente artesanal. «Él lo hacía todo: se inventaba las frases y dibujaba los ejercicios, y luego un delineante los pasaba a limpio. De ahí, a la imprenta», recuerda su hijo Enrique. Así de natural, familiar y artesano. A veces hasta extremos que rozan lo entrañable: las dos manos que han figurado durante décadas en la contraportada de los cuadernos -una sujetando bien la pluma, y la otra, mal- fueron obra de Cipriano, el hermano de la cuidadora de los hijos de Ramón, que trabajaba de cartero y tenía mucho manejo con el dibujo ${ }^{18}$. Inicialmente los cuadernos estaban dirigidos a sus alumnos de la academia, pero enseguida vio que podían ser implantados como complemento a la enseñanza impartida en los colegios españoles. Los contenidos de los cuadernos se referían a la Educación Primaria y Ramón Rubio los ofertó a centros educativos de ese nivel ${ }^{19}$.

En los años setenta y ochenta, Cuadernos Rubio llegó a vender hasta diez millones de ejemplares anuales. Por muy poco dinero $-1,5$ pesetas en 1960, 22 en el año 1982-, era posible adquirir en las papelerías unas libretas llenas de ejercicios para entrenar a los menores. Se utilizaron como complemento de los aprendizajes escolares, pero también como cuadernos de vacaciones, adquiridos por los propios padres. A mediados de los años ochenta del pasado siglo, las principales

16 Álvarez, P. «Cuadernos Rubio, el empeño de un profesor valenciano», Cinco días, 20-oI2017, Recuperable en https://cincodias.elpais.com/cincodias/2017/or/20/sentidos/I484934857_6r4746.

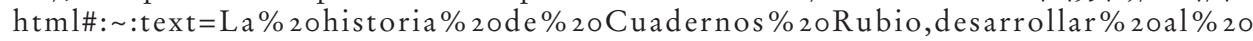
$\mathrm{m} \% \mathrm{C}_{3} \%$ Arxi $\% \mathrm{E}_{2} \% 80 \% \mathrm{~A} 6$.

${ }_{17}$ Cubells, M.: Mi mamá me mima. Las letras y los números de nuestra infancia, Barcelona: Espasa, 2015, p. 31.

18 Fernández, J. «Cuadernos Rubio: Nostalgia del cálculo y la caligrafía», El Periódico, 02/I2/20I5. Recuperable en https://www.elperiodico.com/es/dominical/20I5I202/cuadernos-rubioaprender-caligrafia-cole-4720970.

19 Cubells, M.: Mi mamá me mima..., 20I5, pp. 6o-63. 
editoriales españolas empezaron a publicar cuadernos muy parecidos. Hasta entonces, Ediciones Técnicas Rubio casi tenía la exclusiva del mercado.

En 1999 Enrique Rubio toma la dirección de la empresa que fundó su padre e inicia una renovación: publicidad televisiva y cambios en el diseño; además, se modificaron los contenidos: se pretendía que las frases de la caligrafía o los problemas de cálculo se reorientaran para promover valores de igualdad, suprimiendo frases que vinculaban a las niñas con las muñecas y a los niños con las armas, y para fomentar el cuidado del medio ambiente, la tolerancia, el ahorro, etc. En 2OII se unificó el logotipo de los cuadernos ${ }^{20}$.

La editorial lanzó en zorz la aplicación iCuadernos, y se convirtió en una de las más descargadas de Apple en el segmento educativo ${ }^{21}$. No obstante, el 99,5\% de las ventas sigue siendo en formato papel a pesar de que ya hay tabletas en las que se puede escribir. Desde sus comienzos han pasado más de 60 años y más de 300 millones de cuadernos editados que forman parte de la memoria colectiva. En la actualidad, la firma está presente en países como Alemania, Suiza, Austria, también en México, Brasil, Chile, Estados Unidos, y colabora en Sierra Leona con una escuela infantil ${ }^{22}$.

\section{Los Cuadernos Rubio de aritmética}

La colección de cuadernos de aritmética consta, desde su inicio en 1959, de 25 cuadernos. Los doce primeros están dedicados al aprendizaje de los algoritmos de las operaciones aritméticas elementales.

El índice de estos cuadernos en la edición de 1959 era:

I. Ejercicios primarios de sumas.- 2 sumandos.

I A. Ejercicios primarios de sumas.- 3, 4 y 5 sumandos.

2. Ejercicios primarios de restas.

2 A. Ejercicios primarios de restas con mayor dificultad.

3. Ejercicios primarios de multiplicaciones por una cifra.

$3 \mathrm{~A}$. Ejercicios primarios de multiplicaciones por varias cifras.

4. Ejercicios primarios de divisiones por una cifra.

$4 \mathrm{~A}$. Ejercicios primarios de divisiones por varias cifras.

5. Sumar, restar, multiplicar y dividir enteros.

5 A. Sumar, restar, multiplicar y dividir enteros con mayor dificultad.

6. Sumar, restar, multiplicar y dividir decimales.

20 Cuenca, J.: «Escribir la crisis desde la renovación», Levante-El Mercantil Valenciano, 3I-0320I4. Recuperable en https://www.levante-emv.com/mercantil-valenciano/20I4/o3/3I/escribir-crisisrenovacion/I0960I4.html.

${ }^{21}$ Zafra, I.: «Cómo los cuadernos Rubio han sobrevivido en la era digital», El País, o2-03-20I9. Recuperable en https://elpais.com/economia/2019/02/27/actualidad/I551290632_028596.html.

${ }_{22}$ Álvarez, P.: «Cuadernos Rubio...», op. cit., 2017. 
6 A. Sumar, restar, multiplicar y dividir decimales con mayor dificultad.

En la segunda edición (I977) se cambió la denominación de los cuadernos i a 2A: I. Sumar.- Sin llevar; I A. Sumar.- Llevando; 2. Restar.- Sin llevar; 2 A. Restar.- Llevando. Estos títulos se han mantenido hasta la actualidad.

Los trece cuadernos restantes, numerados del 7 al i9, incluyen la resolución de problemas aritméticos y tienen una estructura diferente en la primera edición de 1959 y en las restantes, publicadas a partir de 1978. En la primera edición, los cuadernos estaban divididos en «ejercicios», cada uno de los cuales se presentaba como el trabajo que se debía realizar un día laborable, y constaba de operaciones y problemas. En 1978 se cambió la orientación de estos cuadernos, centrándolos en la resolución de problemas «sencillos, variados y graduados», y organizados teniendo en cuenta el ámbito numérico y las operaciones que se podían utilizar en la resolución. El título de estos trece cuadernos, que se recoge a continuación, no cambió a partir de 1978 :

7.-Sumar y restar sin llevar.

8.- Sumar llevando y restar sin llevar.

9.- Sumar y restar llevando.

IO, II, I2.- Sumar, restar y multiplicar por una cifra.

I3.- Sumar, restar, multiplicar y dividir por una cifra.

I4, I5, I6.- Sumar, restar, multiplicar por varias cifras y dividir por una cifra.

I7, I8, I9.- Sumar, restar, multiplicar y dividir por varias cifras.

Desde 1959 hasta la actualidad se han publicado los cuadernos Rubio de aritmética. A lo largo de estos 60 años han sufrido variaciones, pero determinar la fecha en que se han producido presenta dificultades. El análisis de los cuadernos nos ha permitido diferenciar seis épocas de los mismos (Figura I).

Figura I. Portadas del cuaderno o de operaciones aritméticas de Rubio.

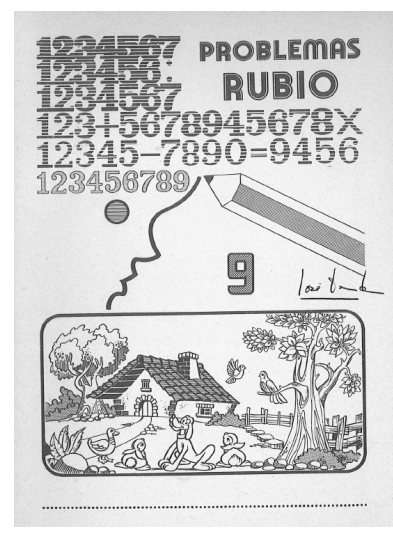

Época 1

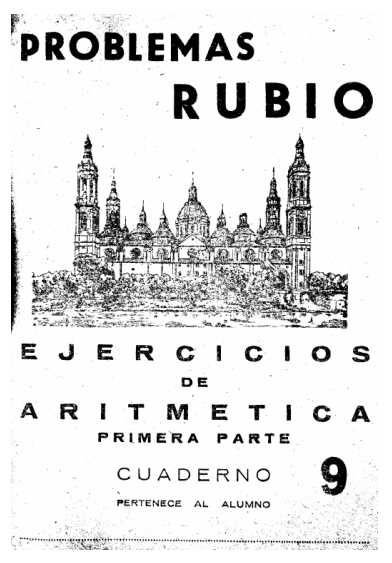

Época 2

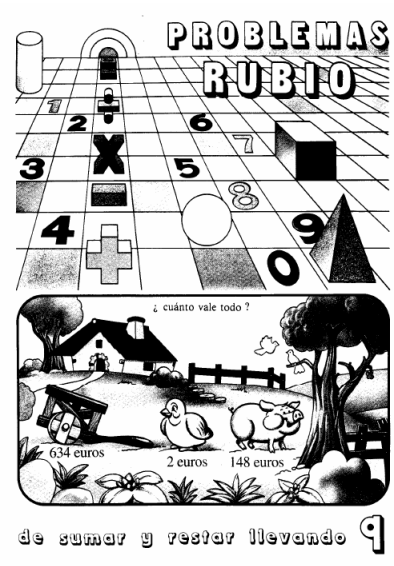

Época 3 


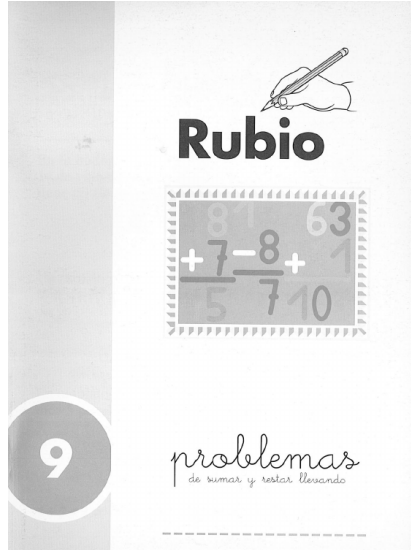

Época 4

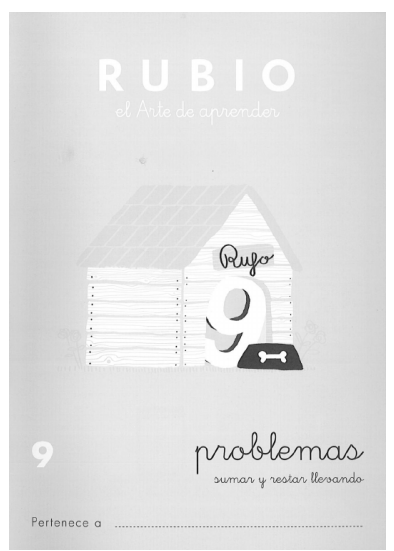

Época 5 y 6

Fuente: Fondo de cuadernos escolares del CEME.

La primera época se corresponde con los 25 cuadernos editados en 1959, con un único código de depósito legal para todos ellos.

La segunda época se corresponde con los editados en 1977 (para los cuadernos de operaciones) y 1978 (para los cuadernos de problemas); en ella cada cuaderno tiene un código de depósito legal diferente, y ese código se ha mantenido en el tiempo. Hubo una reducción del número de páginas de los cuadernos con respecto a la época anterior (desde entonces tienen 20 páginas) y, según su contraportada, están «orientados a la E.G.B.»; hay que tener en cuenta que, en los años 70 del siglo xx, cambió la estructura del sistema educativo español, unificando los ocho primeros niveles educativos obligatorios en una única etapa: la Educación General Básica (EGB).

La tercera época se caracteriza por las ilustraciones en color de las portadas. Se pueden diferenciar dos subépocas, una en la que la moneda utilizada era la peseta (anterior, por tanto, a 2002) y en la que los cuadernos estaban «exentos de ISBN», y otra en la que utilizan euros y tienen ISBN, conservando el mismo depósito legal de 1977 y 1978. Los cuadernos de la primera subetapa siguen señalando que están «orientados a la E.G.B.», a pesar de que la estructura del sistema educativo español había cambiado en 1990 con la Ley Orgánica General del Sistema Educativo (LOGSE), y el octavo curso de EGB se impartió por última vez en el curso 1996-97. En la segunda subetapa (2002) no se hace referencia a la EGB.

La cuarta etapa se identifica también por el cambio en el diseño de las portadas, tras el fallecimiento del fundador, siendo director de la empresa su hijo Enrique Rubio ${ }^{23}$. No se ha podido determinar la fecha en la que estos cuadernos comenzaron a publicarse.

${ }_{23}$ Cubells, M.: Mi mamá me mima..., 2015, pp. I85-I86. 
En la época 5 (aproximadamente desde 2008) se volvió a cambiar el diseño de la portada de los cuadernos: «Una empresa creativa rehace el diseño para estar en sintonía con los nuevos tiempos y consigue, sin perder la esencia, una portada nueva y una bonita y fresca imagen de marca» ${ }^{24}$. Hasta esta época, el contenido estaba impreso en blanco y negro.

La época 6 se identifica por el uso del color en el contenido, siendo las cubiertas iguales a las de la época anterior. Para estos cambios, la empresa contrató a un grupo de expertos (grafólogos, dibujantes y pedagogos) ${ }^{25}$. A partir de 2015, los cuadernos incorporaron la fecha de impresión, aunque de esta época 6 hay cuadernos anteriores.

Los cuadernos Rubio se han utilizado como complemento del trabajo escolar, bien para afianzar las técnicas de cálculo de operaciones aritméticas que se estaban abordando en la escuela, bien para ser realizados durante las vacaciones escolares. La recomendación de uso de los cuadernos no siempre tenía su origen en el profesorado; los cuadernos Rubio se han comercializado a través de las papelerías de barrio o de pueblo y han podido ser fácilmente adquiridos por los padres, a veces en base a sus propias experiencias con ellos. Por ello, no se han asociado a edades ni a cursos de la Educación Primaria, sino a operaciones aritméticas que había que practicar. Solo en los últimos cuadernos, los editados a partir de 2016, la contraportada incluye un cuadro en el que se asocian los 25 cuadernos de aritmética con edades (6-II años) correspondientes a los seis cursos de la Educación Primaria.

\section{El campo conceptual de las estructuras aditivas}

Para el análisis de estos cuadernos vamos a utilizar la categorización de los problemas de sumar y restar elaborada por G. Vergnaud en el marco de su teoría de los Campos Conceptuales (CC) ${ }^{26}$ : el campo conceptual de las estructuras aditivas.

Para Vergnaud, «un concepto no puede ser reducido a su definición, al menos si estamos interesados en su aprendizaje y en su enseñanza. Es a través de situaciones y problemas a resolver como un concepto adquiere sentido para el niño» ${ }^{27}$. Por ello, la teoría de los CC considera el proceso de elaboración pragmática de los conceptos, a partir de situaciones, mediante la construcción y uso de esquemas, "organizaciones invariantes de la conducta para una clase de situaciones dada ${ }^{28}$. Un concepto es considerado como una tripleta de tres conjuntos: $\mathrm{C}=$

24 Ibid., p. 20I.

${ }_{25}$ Ibid., p. 20I.

26 Vergnaud, G. : «La théorie des champs conceptuels», op. cit., I99i. Vergnaud, G. : El niño, las matemáticas..., op. cit., 2016.

${ }^{27}$ Vergnaud, G. : «La théorie des champs conceptuels», op. cit., I99I, p. I35.

${ }_{28}$ Ibid., p. 136. 
$(\mathrm{S}, \mathrm{I}, s)$, donde $\mathrm{S}$ es el conjunto de situaciones que dan sentido al concepto pues constituyen la referencia del mismo; I es el significado del concepto y se identifica con los esquemas que permiten actuar sobre las situaciones y con las propiedades del concepto; y s, que es el significante, las diferentes formas de representación del concepto y sus propiedades, así como las formas de representar las situaciones y su tratamiento. La definición pragmática del concepto apela, así, al «conjunto de situaciones que constituyen la referencia de sus diferentes propiedades y al conjunto de los esquemas empleados por los sujetos en esas situaciones» ${ }^{29}$.

Puesto que en los cuadernos Rubio de problemas no se hacen explícitos los posibles procedimientos de resolución ni, incluso, las formas de expresarlos, se centrará el análisis en otra noción central de la teoría de los CC: las clases de situaciones aditivas que se abordan en los cuadernos. Flückiger señala que la expresión clase de situaciones, utilizada por Vergnaud, «está próxima a la de clase de problemas y no se corresponde con la acepción de la palabra situación en la teoría de las situaciones de Brousseau» ${ }^{30}$ que le da un alcance didáctico. Vergnaud limita el término situación al «sentido que se le da habitualmente en psicología» ${ }^{31}$.

El campo conceptual de las estructuras aditivas es «el conjunto de las situaciones cuyo tratamiento implica una o varias sumas o restas y el conjunto de los conceptos y teoremas que permitan analizar esas situaciones como tareas matemáticas» ${ }^{32}$.

Considerando un concepto $C$ como la tripleta $C=(S, I, s)$, el sentido que tiene dicho concepto para una persona es la tripleta de subconjuntos que dicha persona asocia al concepto $\mathrm{C}$. En el caso de la suma y la resta, es el conjunto de situaciones que identifica como de sumar y restar; los esquemas que puede usar para actuar sobre dichas situaciones, y las formas de representación que conoce, tanto sobre las situaciones y su resolución como sobre los propios esquemas. El sentido que tiene un concepto para una persona no se construye de una vez completamente, sino que va variando al evolucionar y enriquecerse esa tripleta personal. Como recuerda Flückiger, «es a través de las situaciones didácticas como los esquemas ya construidos pueden ser desestabilizados para ser enriquecidos» ${ }^{33}$.

La gestión a largo plazo, por parte del profesor, del proceso de aprendizaje requiere realizar un análisis de los conceptos involucrados que le sirva de base para plantear una sucesión de situaciones, desde las más sencillas, es decir, aquellas para las que los estudiantes tienen algún tipo de esquema que les permite abordarlas, hasta aquellas que la institución en la que se lleva a cabo el proceso de aprendizaje considera como idóneas. Hay que tener en cuenta que también existe el sentido de un concepto $\mathrm{C}$ en una institución: es la tripleta formada por las si-

29 Ibid., p. I45.

30 FLÜCKIGER, A.: «Analyse didactique et schème: une étude qui articule Théorie des Situations et Théorie des Champs Conceptuels", Recherches en Didactique des Mathématiques, 24, 2-3 (2004), pp. 169-204, cita en p. 176.

${ }^{31}$ Vergnaud, G.: «La théorie des champs conceptuels», op. cit., I99I, p. I50.

32 Ibid., I99I, p. I47.

33 FlüCKIger, A.: «Analyse didactique...», 2004, p. 177. 
tuaciones que se considera que los estudiantes de esa institución deben asociar al concepto, los esquemas y propiedades que se pueden utilizar para abordar esas situaciones y las formas de representación que se consideran en dicha institución ${ }^{34}$. Este trabajo se desarrolla en la institución Educación Primaria, pero también se consideran instituciones menos amplias como los diferentes cursos o etapas de la Educación Primaria, por cuanto en ellas se puede considerar un sentido específico del campo conceptual de las estructuras aditivas.

Hay una gran variedad de situaciones que se pueden resolver mediante sumas y restas y muchas de ellas se pueden descomponer en otras más simples del mismo CC; así hay problemas de una etapa, que se pueden resolver con una única operación de suma o resta, y problemas de varias etapas, que requieren de varias operaciones. En un problema típico de una etapa, hay dos frases con datos numéricos y una cuestión, planteada de forma más o menos explícita, y que vamos a denominar la incógnita del problema, cuya solución es una frase en la que interviene un número, obtenido a partir de los datos mediante una suma o una resta.

Para analizar los problemas de este CC hay que tener en cuenta la función de los números que intervienen en los datos y en la incógnita ${ }^{35}$; según esta función pueden ser:

- Estados, con distinta significación de los mismos, es decir, pueden ser el cardinal de una colección, el ordinal de un elemento dentro de un conjunto ordenado o la medida de una cantidad continua.

- Pueden expresar transformaciones de un estado en otro; estas transformaciones pueden ser positivas (de aumento) o negativas (de disminución).

- Pueden expresar, de forma numérica, una comparación entre dos estados, de forma positiva («es más... que») o negativa («es menos... que»).

De acuerdo con estas funciones, Vergnaud identifica seis categorías de situaciones aditivas:

- Tipo I (E-E-E): dos estados (parciales) se combinan para formar otro estado (el total).

- Tipo II (E-T-E): un estado inicial experimenta una transformación a un estado final.

- Tipo III (E-C-E): dos estados se comparan y se expresa numéricamente dicha comparación. Los dos estados no son equivalentes: se determina uno (estado 2) en relación al otro (estado 1) que sirve de base. Por ejemplo, en la comparación «Lucía tiene tres años más que Silvia», se expresan los años de Lucía (estado 2) con respecto a los años que tiene Silvia (estado 1), que sirven de base de la comparación.

- Tipo IV (T-T-T): se componen dos transformaciones para dar una trans-

34 Carrillo Gallego, D.; SaÁ Rojo, M. D. y Sánchez Jiménez, E.: «Favorecer el aprendizaje matemático con sentido en la Educación Infantil: un reto». Ponencia invitada en las I7 JAEM, Cartagena, 2015. Recuperable en http://I7jaem.semrm.com/aportaciones/po2.pdf.

${ }_{35}$ El análisis realizado se basa en Vergnaud, G.: El niño, las matemáticas..., 2016, pp. I6I-184, aunque también se ha considerado que el significado de los números puede ser ordinal. 
formación total.

- Tipo V (C-T-C): interviene una comparación inicial entre dos estados; uno de dichos estados sufre una transformación cambiando la relación entre los estados (comparación final).

- Tipo VI (C-C-C): de tres estados desconocidos, se conocen dos relaciones entre ellos y hay que calcular la tercera comparación.

La Figura II recoge los esquemas de las seis categorías de situaciones aditivas.

Figura II. Esquemas gráficos de los seis tipos de situaciones aditivas

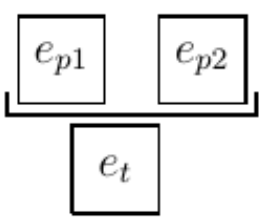

Tipo I

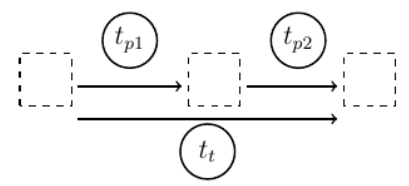

Tipo IV

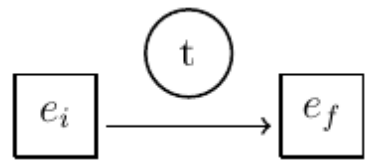

Tipo II

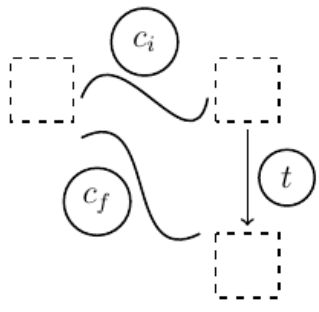

Tipo V

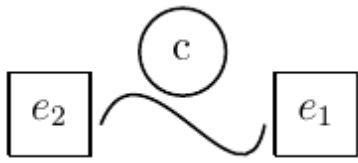

Tipo III

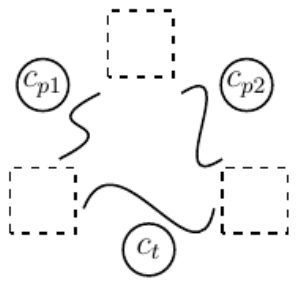

Tipo VI

Dentro de estas categorías se pueden definir subcategorías, dependiendo del papel de la incógnita. En este trabajo se han utilizado las siguientes:

- Tipo I: IP (incógnita un estado parcial) y IT (incógnita el estado total).

- Tipo II: $2 F$ (incógnita el estado final), $2 T$ (incógnita la transformación) y $2 I$ (incógnita el estado inicial.

- Tipo III: 3.2 (incógnita el estado 2 de la comparación), ${ }_{3} C$ (incógnita la comparación) y 3.I (incógnita el estado I de la comparación, la base de la comparación).

- Tipo IV: $4 T$ (incógnita la transformación total) y ${ }_{4} P$ (incógnita una de las transformaciones parciales).

- Tipo V: $5 F$ (incógnita la comparación final), $5 T$ (incógnita la transformación) y $5 I$ (incógnita la comparación inicial).

- Tipo VI: Puesto que las tres posibles comparaciones entre los tres estados son equivalentes, en todos ellos la incógnita es la comparación total. 
Aunque los problemas se resuelvan con la misma operación aritmética, el tipo y subtipo de problema y el significado del número influyen en la dificultad relativa de los mismos y en la identificación de las técnicas que pueden ser utilizadas en su resolución, con un desfase que puede ser de varios años ${ }^{36}$.

Además del tipo y subtipo de la situación y del significado del número en ellas, hay variables matemáticas que influyen en los esquemas y propiedades a aplicar en la resolución de la situación y en su representación, como el campo numérico (números naturales, enteros, fracciones, decimales, reales...), el tamaño de los números, la posibilidad de resolución mediante cálculo mental... Otras variables que amplían la referencia del CC e influyen en la dificultad de resolución son el orden en la presentación de los datos y la incógnita; el contexto, más o menos conocido por el resolutor, a que hace referencia la situación; el uso de términos asociados a la operación que resuelve la situación o a otras; la existencia de datos superfluos o de datos no explícitos...

\section{Análisis de problemas de sumas y restas en los cuadernos Rubio}

Se han analizado los cuadernos Rubio 7, 8 y 9, dedicados a problemas que se resuelven con sumas y restas, en la época 2 , la primera en la que se hace referencia explícita y exclusiva a problemas, utilizando las categorías identificadas por Gerard Vergnaud para el campo conceptual de las estructuras aditivas; estos cuadernos corresponderían a los dos primeros cursos de la Educación Primaria, según la contraportada de los últimos cuadernos editados. Se contrastarán los resultados con el análisis de las situaciones de sumar y restar que aparecen en cuadernos posteriores, dedicados a problemas que se resuelven con todas las operaciones aritméticas, concretamente en el is y en el 19, que pueden asociarse a los cursos $4 .^{\circ}$ y $6 .^{\circ}$ de la Educación Primaria, respectivamente. En un apartado posterior se estudiarán las posibles variaciones que experimentaron esas situaciones aditivas en ediciones posteriores de los cuadernos.

La estructura de los cuadernos de problemas se mantiene constante de la época 2 a la 5; son cuadernos de 20 páginas y, en general, en cada una de ellas, hay un problema planteado de forma gráfica y tres problemas verbales con espacio libre para efectuar la resolución; en la última línea hay dos operaciones, en disposición horizontal. En los cuadernos i6 y i7 hay dos problemas gráficos y dos verbales en las páginas i y 20, y en los cuadernos i8 y ig hay dos problemas gráficos y dos verbales en la página I. Por tanto, en cada cuaderno hay 80 problemas.

Bastantes de los problemas gráficos de estos cuadernos (del tipo I, con incógnita el estado final, y del tipo 2, en ambos casos con significado del número cardinal) se pueden resolver contando algunas imágenes del dibujo, sin necesidad de realizar una operación aritmética, pero se han considerado como problemas

36 Vergnaud, G. «La théorie des champs conceptuels», op. cit., I99I, p. I52. 
pues la representación gráfica sugiere la operación a realizar y puede contribuir a dar sentido a dicha operación. Sin embargo, hay otros (7.2.I, 7.6.I, 8.3.I, 9.I.I y 9. I2.I $^{37}$ en los que no hay una operación asociada y se han considerado como situaciones de contar.

También hay problemas verbales en los que para dar la respuesta no hay que hacer ninguna operación, pues lo que se pide es uno de los datos, como es el caso del problema 9.I9.3: «En una cesta había 6 manzanas y i4 peras. Nos comemos las 6 manzanas. ¿Cuántas peras quedan en la cesta?».

En el cuaderno 7, todos los problemas (78) son de una etapa, aunque algunos de tipo IT requieran una suma de varios sumandos; en el cuaderno 8 hay 67 de una etapa y I2 de 2, y en el cuaderno 9, hay 40 problemas de una etapa, 36 de dos $\mathrm{y}$ uno de tres.

El tipo de problema (etapa), según la clasificación de Vergnaud, se recoge en la Tabla I. De las 288 situaciones aditivas analizadas en los tres cuadernos (7, 8 y 9), la mayoría (I25, 43\%) son del tipo 2 con incógnita el estado final. También son frecuentes las situaciones de tipo i con incógnita el estado total $(85,30 \%)$ y, en tercer lugar, las de tipo 3 con incógnita la comparación (42, 15\%). No hay ninguna de los tipos 5 y 6 ni del tipo 4 con incógnita una transformación parcial, ni del tipo 3 con incógnita el estado I. En los tres problemas de tipo $4 \mathrm{~T}$, los datos son transformaciones parciales del mismo sentido, todas positivas (7.17.4 y 8.6.3) o todas negativas (7.I0.4), cuya interpretación está próxima a una situación de tipo I con incógnita el estado total, y son los más sencillos de este tipo ${ }^{38}$.

El significado de las cantidades que aparecen en los problemas es mayoritariamente cardinal (195, 68\%); no hay ninguna situación con significado ordinal. El significado medida va aumentando paulatinamente, 7, I5 y 23 situaciones en los cuadernos 7, 8 y 9, respectivamente; la mayoría (39) hacen referencia al dinero y 6 (dos en cada cuaderno) al tiempo, usando como unidades el año y el día.

Tabla I. Clasificación de las situaciones aditivas de los cuadernos Rubio 7, 8, 9, Is y ig (época 2).

\begin{tabular}{|c|c|c|c|c|c|}
\hline & \multicolumn{5}{|c|}{ CUADERNO } \\
\hline Tipo & 7 & 8 & 9 & I5 & I9 \\
\hline Contar & 2 & I & 2 & 0 & 0 \\
\hline IT & 23 & 30 & 32 & I6 & 26 \\
\hline IP & I & 5 & 6 & 8 & 9 \\
\hline $2 \mathrm{~F}$ & 36 & 39 & 50 & 8 & 9 \\
\hline $2 \mathrm{~T}$ & $\mathrm{I}$ & 2 & 2 & $\mathrm{I}$ & 5 \\
\hline $2 \mathrm{I}$ & 7 & $\mathrm{I}$ & 3 & 0 & 2 \\
\hline
\end{tabular}

${ }^{37}$ Se han identificado los problemas con un código de tres números, que corresponden al número de cuaderno, el número de página y el número de orden del problema dentro de la página.

${ }^{38}$ Vergnaud, G.: El niño, las matemáticas..., 2016, p. I80. 


\begin{tabular}{|c|c|c|c|c|c|}
\hline 3.2 & 0 & 0 & 5 & I & 5 \\
\hline${ }_{3} \mathrm{C}$ & 9 & I4 & I9 & 3 & 8 \\
\hline 3.I & 0 & 0 & 0 & 0 & 0 \\
\hline${ }_{4} \mathrm{~T}$ & 2 & I & O & 2 & O \\
\hline${ }_{4} \mathrm{P}$ & O & O & O & O & O \\
\hline${ }_{5} \mathrm{~F}$ & 0 & O & O & O & O \\
\hline${ }_{5} \mathrm{~T}$ & 0 & 0 & O & 0 & $\mathrm{O}$ \\
\hline $5 \mathrm{I}$ & O & o & O & o & O \\
\hline 6 & 0 & O & O & 0 & O \\
\hline
\end{tabular}

A partir del número io, los problemas de los cuadernos pueden resolverse utilizando también las operaciones de multiplicar y dividir. Hemos identificado y analizado las situaciones aditivas en dos de estos cuadernos, el i5, que correspondería al final del $4 .^{\circ}$ curso de Primaria, y el 19 , último de la serie, que reflejaría el nivel final que proponen los autores para esta etapa educativa. En el análisis de las etapas que se resuelven con una suma o una resta, hemos tenido en cuenta el tipo de situación según la clasificación de Vergnaud, el significado de las cantidades que aparecen, el campo numérico (puesto que en estos niveles no solo se estudian los números naturales) y el tamaño de los números.

El cuaderno is está dedicado a problemas «de sumar y restar, multiplicar por varias cifras y dividir por una». En 35 de los 80 problemas propuestos hay una etapa aditiva, y dos etapas en otros dos problemas. En la Tabla I se recogen los tipos de las 39 situaciones. No hay tipos nuevos con respecto a los cuadernos 7, 8 y 9 , incluso no hay ninguno del tipo 2 con incógnita el estado inicial. La mayoría $(\mathrm{I} 6+8,62 \%)$ son de tipo I. En los dos problemas de tipo 4, la primera transformación parcial es positiva y mayor que la segunda, que es negativa, lo que hace el problema más fácil pues se puede interpretar la primera transformación como un estado al que se puede quitar el valor del segundo dato.

El número de situaciones en las que intervienen magnitudes aumenta y se diversifica: hay diez situaciones de dinero, ocho sobre peso, con unidad el kilogramo; cuatro de longitud, con unidades el kilómetro y el metro, y tres de tiempo, con unidades el año y el día. Hay una situación en la que aparecen números de seis cifras y dos con números de cinco cifras; en el resto los números son de cuatro cifras o menos.

El cuaderno I9 es sobre problemas «de sumar y restar. Multiplicar y dividir por varias cifras». La mayoría de los problemas son de varias etapas. En 48 de los 80 problemas del cuaderno hay alguna etapa aditiva (en un caso, hasta cuatro); el número de etapas aditivas que se han localizado es 64. En la Tabla I se recogen los tipos de situaciones aditivas de este cuaderno, que son las mismas que en el cuaderno 9; las más abundantes son las de tipo I (35, 55\%), hay i6 (25\%) de tipo 2 y $13(20 \%)$ de tipo 3. No hay situaciones de los tipos 4,5 y 6 y tampoco del tipo 3 
con incógnita el estado i. Hay seis situaciones con números de seis cifras, nueve con números de cinco cifras y el resto de números que intervienen son menores.

En este cuaderno hay dos problemas (19.12.4 y 19.20.4) en los que el significado del número es diferente en las dos etapas aditivas que tienen. Hay i4 situaciones con significado cardinal y 36 que se refieren a magnitudes como el dinero ( $\mathrm{I} 3$, pesetas), el peso (I2, siendo las unidades la tonelada, el kilogramo y el gramo), la capacidad ( 5 , medida en $\mathrm{m}^{3}$ y litros), la longitud ( 4 , con el $\mathrm{km}$ y el metro como unidades) y el tiempo (I, días). El problema 19.6.3 («Un joven tenía I2 años en 1978 , ¿en qué año cumplirá 28 ?») se refiere a posiciones temporales pues se trata de situar acontecimientos en el conjunto ordenado que es la línea del tiempo; el significado de estos números es, por tanto, ordinal. En ningún cuaderno (del 7 al ig) se han localizado problemas de significado ordinal en colecciones, solo de posiciones temporales.

En este cuaderno, que se considera apropiado para el final de la Educación Primaria, el único campo numérico que se utiliza es el de los naturales; en los problemas sobre magnitudes las cantidades se expresan con un número entero de unidades; solo en el problema 19.17.3, que no tiene ninguna etapa aditiva, hay una longitud expresada con un decimal. Sin embargo, el cuaderno 6A, que se considera de este nivel, está dedicado al aprendizaje de las operaciones de «sumar, restar, multiplicar y dividir decimales» y sus ejercicios son bastante más complejos que las operaciones que intervienen en el cuaderno 19: con mayor número de cifras y con varias cifras decimales.

\section{Los Cuadernos Rubio de sumas y restas a lo largo del tiempo}

En el apartado «Los cuadernos Rubio de aritmética» se han descrito las distintas épocas que caracterizan la evolución de estas publicaciones. El análisis llevado a cabo en el apartado inmediatamente anterior se ha centrado en algunos cuadernos seleccionados de la época 2. Analizamos a continuación la evolución de estos cuadernos desde la época 2 hasta la época 6.

La época 3 se caracteriza por que las tapas de los cuadernos son de varios colores. En esta época se distinguen dos subetapas, una en la que la unidad monetaria utilizada es la peseta y otra (a partir del año 2002) en la que es el euro. Los cuadernos de la época 2 habían supuesto un cambio, con respecto a los de la época I, para "orientarlos a la E.G.B.»; a pesar de que la EGB desapareció con una nueva ley de educación (la LOGSE, 1990), esa mención a la EGB continúa en los cuadernos de la primera subépoca, en la cual el único cambio en los cuadernos fue en las portadas.

En la segunda subépoca, en la que ya no se hace referencia a la EGB, los cuadernos se adaptaron al cambio de la moneda oficial desde la peseta al euro (2002). Se introduce el manejo de la nueva moneda en todos los ejercicios relacionados con el dinero. En los cuadernos 7, 8 y 9, recomendados para edades correspondientes a los primeros cursos de la Educación Primaria, al cambiar la moneda se 
actualizaron los problemas en los que aparecen cantidades de dinero. Por ejemplo, el problema 8.2.3, que en la subépoca anterior era: «He ido a comprar a la tienda con 45 pesetas y he vuelto a casa con I2. ¿Cuánto he gastado?», cambia a: «He ido a comprar a la tienda con 45 euros y he vuelto a casa con I2. ¿Cuánto he gastado?»; o el 8.9.2, que pasa de «Las cerezas que hay en un plato valen 35 pesetas y las de otro 47. ¿Cuánto valen todas juntas?» a «Las cerezas que hay en un plato valen 35 céntimos y las de otro 47 . ¿Cuánto valen todas juntas?»; en estos casos, los números que aparecen son los mismos y es la misma operación. En otros problemas, como el 8.8.4 («Mi mamá me manda a la tienda con 85 pesetas para comprar una botella de aceite y me devuelven 4 pesetas. ¿Cuánto vale la botella de aceite?») que se transforma en «Mi mamá me manda a la tienda con io euros para comprar una botella de aceite y me devuelven 7 euros. ¿Cuánto vale la botella de aceite?», se han cambiado las cantidades para darles mayor verosimilitud, pero el enunciado es, prácticamente, el mismo y el problema es del mismo tipo. Las cantidades expresadas en pesetas se modifican para que pasen a estar expresadas en euros o en céntimos (de euros) sin mezclar ambas unidades, lo que permite seguir resolviendo los problemas operando con números enteros. En otros cuadernos como el is o el I9, recomendados para edades superiores, se han realizado cambios similares, pero las cantidades de euros se expresan, en muchas ocasiones, con números decimales, como en el problema 15.9.4 que era: «Compramos un artículo por 4.312 pesetas y pagamos I34 pesetas de gastos. ¿Por cuánto hemos de venderlo para no perder ni ganar?» y se transforma en «Compramos un artículo por 139,6 euros y pagamos 13,4 euros de gastos. ¿Por cuánto hemos de venderlo para no perder ni ganar?»; por tanto, en estos cuadernos es necesario operar con números decimales para poder resolver los problemas.

El contenido de los cuadernos de las épocas 4 y 5 es el mismo, solo cambian las tapas. Comparándolos con los de épocas anteriores se ve que se mantienen las estructuras lógicas y matemáticas de los problemas, pero se adecúa la redacción de los enunciados. Se adaptan a las nuevas sensibilidades presentes en la educación y a los cambios sociales. Veamos algunos ejemplos de cambios. El problema 7.3.3, «Un oficial del ejército tenía 4 condecoraciones y le dieron 3 más. ¿Cuántas condecoraciones tendrá ahora?», cambia a «Un atleta consiguió 4 medallas y le dieron 3 más. ¿Cuántas medallas tendrá ahora?»; son problemas del mismo tipo que se resuelven con la misma operación, lo que cambia es el contexto militar a uno deportivo. En el problema 7.3.2, «Ramón tenía 5 tebeos y su hermano Enrique le quita 2. ¿Cuántos tebeos le quedan a Ramón?», han cambiado la situación para que un hermano no le quite cosas al otro, sino que le son regaladas: «Ramón tenía 5 tebeos y le regala 2 a su hermano Enrique. ¿Cuántos tebeos le quedan a Ramón?». Otras situaciones similares están en el problema 15.10.2, «En una formación militar había I2 hileras de I4 soldados cada una y se salieron 8 soldados. ¿Cuántos soldados quedaron en la formación?», que cambió a «En el patio de un colegio hay I2 filas de I4 alumnos. Si 8 niños entran a clase, ¿cuántos quedan en el patio?», y en el problema 15.12.2, que cambia de «Una granada fue lanzada a I.255 metros, faltándole 527 para alcanzar el blanco. ¿A cuántos metros estaba el 
objetivo?» a «Los participantes de un rally llevan recorridos $1.255 \mathrm{~km}$ y hacen una parada cuando les falta $255 \mathrm{~km}$ para llegar a la meta. ¿Cuántos kilómetros recorrerán en total?». En general, se eliminan referencias a animales enjaulados, capturados o confinados en recintos cerrados; por ejemplo, los pájaros enjaulados de un enunciado de la época 3 se sustituyen por palomas en un palomar a partir de la época 4. Se modifican contenidos con posible sesgo de género, por ejemplo, «Pepito» $\mathrm{y}$ «Juanito» de dos enunciados de la época 3 pasan a ser «Eva» $\mathrm{y}$ «Yolanda» en las posteriores. Se eliminan referencias al mundo militar sustituyendo elementos que aparecen hasta la época 3 como son las condecoraciones de un militar, los soldados de un castillo, etc. Se actualizan otros elementos lingüísticos o de contexto, por ejemplo, se cambia el término «estampas» por el de "cromos», aparece el término «ONG» o se sustituye al repartidor de leche por el cartero.

En la época 6 (última), la portada es igual que la de la época 5, pero se ha cambiado el contenido, introduciendo ilustraciones en color; se observa también que se eliminan problemas presentes en las versiones anteriores que no son reemplazados por otros nuevos; se elimina un problema verbal en cada página, que queda con un problema gráfico y dos verbales, y se introducen tres páginas (denominadas de «descanso») que se estructuran de forma distinta porque se describe una situación sobre la que se plantea un número variable de cuestiones. Los problemas están seleccionados entre los del cuaderno de la época anterior y situados, la mayoría de las veces, en la misma página.

Por tanto, en lo que se refiere a la tipología de los problemas que se plantean e, incluso, a los enunciados de los mismos, se observa una gran continuidad a lo largo de las etapas que se han identificado en los cuadernos Rubio de problemas.

\section{Problemas gráficos}

La cuarta parte de los problemas que aparecen en los cuadernos de las épocas 2 a 5 están planteados utilizando representaciones gráficas. En este apartado se trata de caracterizar esas representaciones y comentar su evolución en el tiempo.

Hay problemas gráficos que se resuelven en una etapa y otros en varias. En la Tabla II se recoge la clasificación, siguiendo a Vergnaud, de esas etapas; 69 son de los cuadernos con problemas solo de suma y resta (cuadernos 7,8 y 9) y 23 corresponden a los cuadernos 15 y i9, con problemas en los que también intervienen las operaciones de multiplicar y dividir. El significado del número en los problemas del cuaderno 7 y en casi todos los del cuaderno 8 (excepto dos) es cardinal, mientras que en el cuaderno 9, ocho de los problemas se refieren a precios y en los cuadernos is y ig la práctica totalidad de las situaciones aditivas de los problemas gráficos (excepto dos) involucran medidas; en total hay 57 situaciones cardinales y 35 de medida, que se refieren a dinero (23), peso (Io), longitud y capacidad (uno de cada una); ninguna de estas situaciones está relacionada con el tiempo. 
TABLA II. Clasificación de las situaciones aditivas gráficas de los cuadernos Rubio 7, 8, 9, I5 y I9 (época 2).

\begin{tabular}{|c|c|c|c|c|c|c|c|}
\hline & 7 & 8 & 9 & Total 1 & 15 & 19 & Total \\
\hline Contar & 2 & 1 & 2 & 5 & 0 & 0 & 5 \\
\hline $1 \mathrm{~T}$ & 6 & 10 & 12 & 28 & 6 & 10 & 44 \\
\hline $1 \mathrm{P}$ & 0 & 0 & 2 & 2 & 4 & 1 & 7 \\
\hline $2 \mathrm{~F}$ & 1 & 4 & 3 & 8 & 0 & 0 & 8 \\
\hline $2 \mathrm{~T}$ & 0 & 0 & 0 & 0 & 0 & 0 & 0 \\
\hline $2 \mathrm{I}$ & 4 & 0 & 0 & 4 & 0 & 0 & 4 \\
\hline 3.2 & 0 & 0 & 0 & 0 & 0 & 1 & 1 \\
\hline $3 \mathrm{C}$ & 7 & 6 & 9 & 22 & 0 & 1 & 23 \\
\hline 3.1 & 0 & 0 & 0 & 0 & 0 & 0 & 0 \\
\hline & & & & 69 & & & 92 \\
\hline
\end{tabular}

En general, la cuestión que plantea el problema se expresa de forma verbal y las ilustraciones asociadas presentan datos del problema. Pero la función de la ilustración se relaciona con el tipo de problema y con el significado de los números que intervienen.

En los problemas de tipo I, cuando la incógnita es el estado total y el significado es cardinal, la ilustración suele presentar las colecciones que constituyen los estados parciales; estas situaciones se pueden resolver contando los elementos, pero la partición en subconjuntos evoca la acción de unir a la que se asocia la operación de sumar. Cuando el significado es medida, lo que figura suelen ser objetos a los que se asocia su precio, peso, capacidad, etc.; también puede haber imágenes de monedas (Figura III).

Figura III. Problemas Rubio 8.6.I, 8.I4.I y 8.9.I, de la época 2.

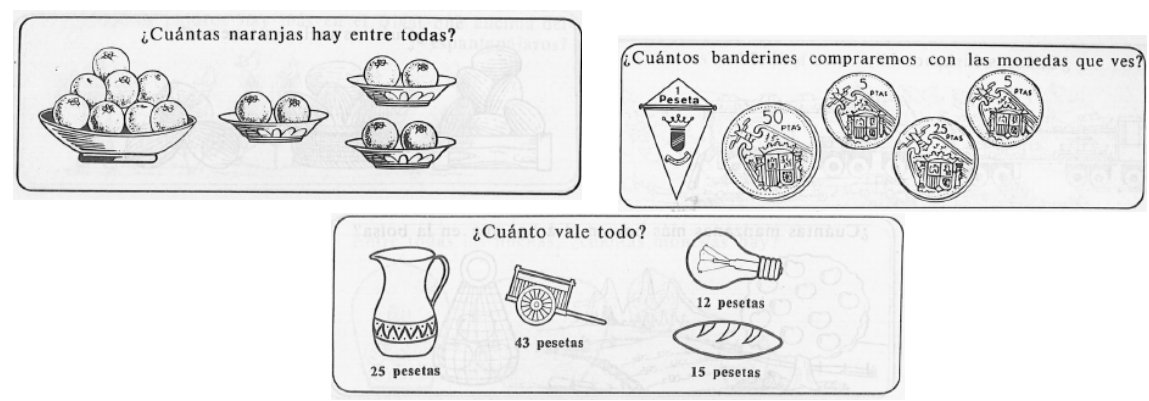

Si la incógnita es uno de los estados parciales, la ilustración puede representar el estado total y la frase que la acompaña plantear cómo hay que formar las subcolecciones. Cuando se trata de medidas, pueden usarse signos de las operaciones 
aritméticas para expresar la acción del problema (Figura IV). En los cuadernos Rubio de operaciones aritméticas, en los problemas gráficos que figuran en los cuadernos i y iA, utilizan el signo + para expresar la unión de colecciones ${ }^{39}$; en estos cuadernos de problemas se utiliza mucho menos esa forma de representación.

Figura IV. Problemas Rubio 9.5.I y I3.I5.I, de la época 2.
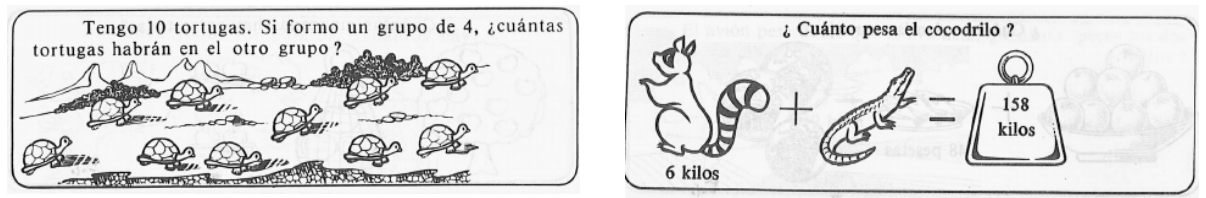

En los problemas de tipo 2, cuando la incógnita es el estado final, unas veces se ha representado el estado inicial, otras la transformación y, en un caso, la secuencia de la situación (7.4.I I ${ }^{40}$. Cuando la incógnita era el estado inicial, representan el estado final y la transformación como en el problema 7.20.I (Figura V).

Figura V. Problemas Rubio 8.I7.I, 8.I5.I, 7.4.I y 7.20.I, de la época 2.
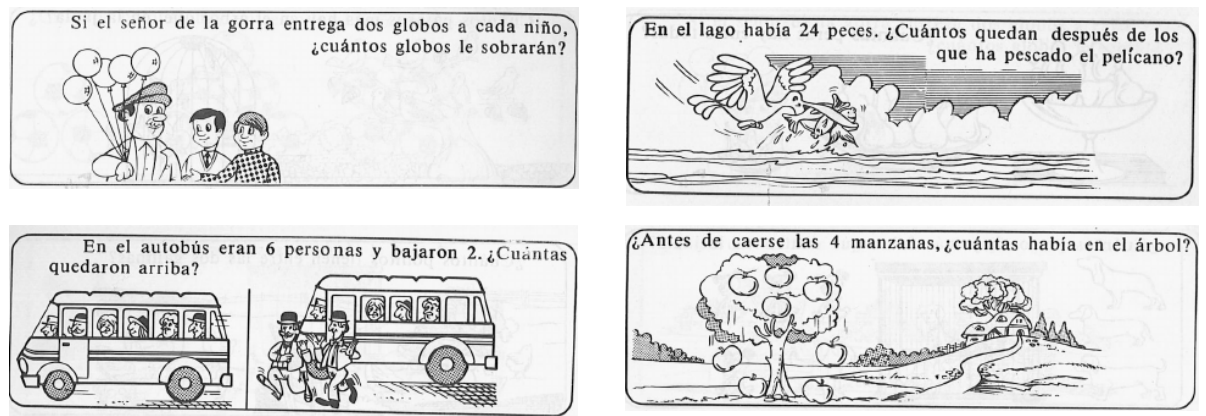

Hay 24 problemas gráficos de tipo 3 y, salvo uno (I9.5.I, Figura VI), lo que se pide es la comparación entre dos colecciones o dos medidas, a las cuales se refieren las imágenes (como en el problema 8.I3.I, Figura VII); o bien se presenta una colección o medida y se plantea una cuestión del tipo «¿Cuánto falta para...?» (problemas 7.II.I y 9.II.I, Figura VIII).

39 Carrillo, D.; Olivares, P. y Castejón, J. F.: «Calcular con los Cuadernos Rubio. Características y evolución desde 1959", Ensino em Re-vista (aceptado).

${ }^{4}$ Esta última forma es la habitual en los problemas de los cuadernos 2 y $2 \mathrm{~A}$, de operaciones de restar. Ibid. 
Figura VI. Problema Rubio 19.5.I de la época 2.

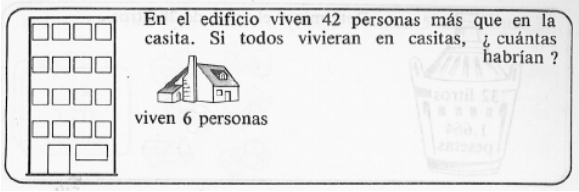

Las imágenes se reutilizan, se recortan, se reorganizan (Figura VII):

FigURA VII. Ejemplo de reutilización de imágenes.

Problemas Rubio 8.I3.I y 9.6.I, de la época 2.
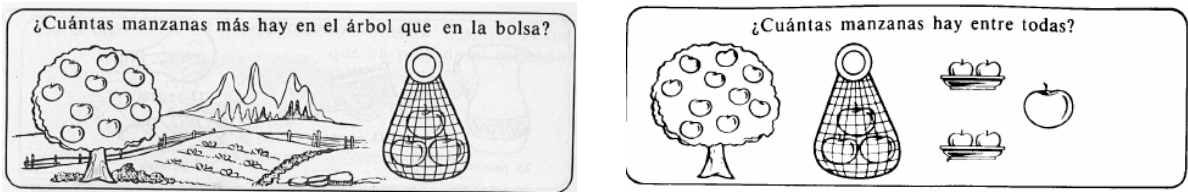

En ocasiones, con una misma imagen, la parte verbal plantea problemas diferentes (Figura VIII):

Figura VIII. Diferentes problemas con la misma imagen.

Problemas Rubio 7.II.I, II.I.I.I, 9.II.I y II.I3.I, de la época 2.
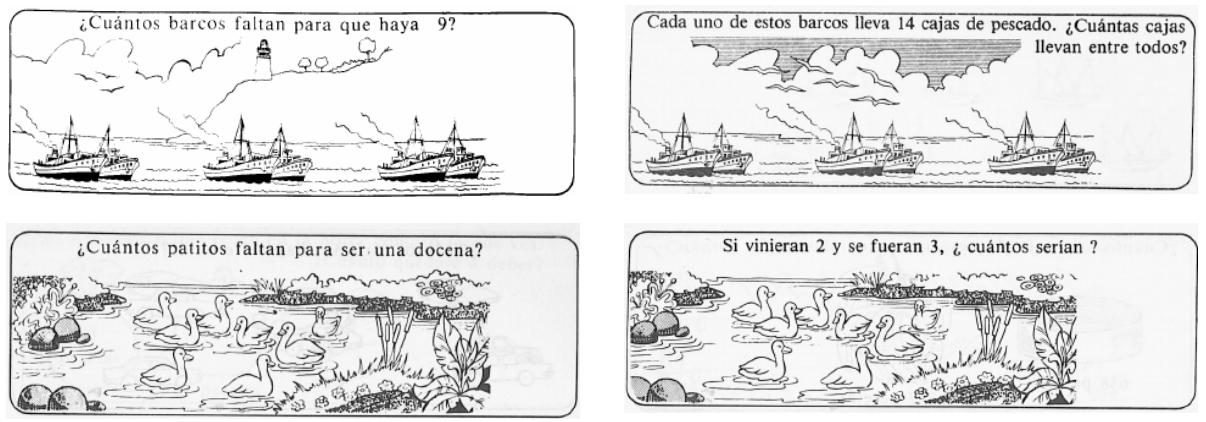

De 1978 a 2002 las ilustraciones fueron las mismas. Con el paso de la peseta al euro como unidad monetaria cambiaron los problemas en los que intervenía el dinero. En ocasiones (como en los problemas 9.8.I, 9.I5.I, 9.I8.I), se cambia de pesetas a céntimos o euros, así como los objetos a los que se refieren, pero la operación es la misma; otras veces cambian las cantidades y la operación, pero el tipo de problema es el mismo (problemas 9.I3.I, I5.6.I) e incluso se mantienen las ilustraciones (problemas 9.20. y en la mayoría de los problemas de dinero de los cuadernos 15 y 19). En estos cuadernos, las cantidades que aparecen en la época 2 
son medidas enteras (números naturales), pero a partir de 2002, en los problemas con dinero se utilizan los números decimales.

En la época 4 se cambiaron las ilustraciones para modernizarlas, tanto en el estilo del dibujo como, en ocasiones, en los objetos representados, pero los problemas son del mismo tipo y se resuelven con la misma operación (Figura IX). Ya se ha dicho que en la época 5 solo se cambió la portada, pero el interior es el mismo que el de la época 4.

FiguRa IX. El problema Rubio 8.5. en la época 2 y la época 4 respectivamente.
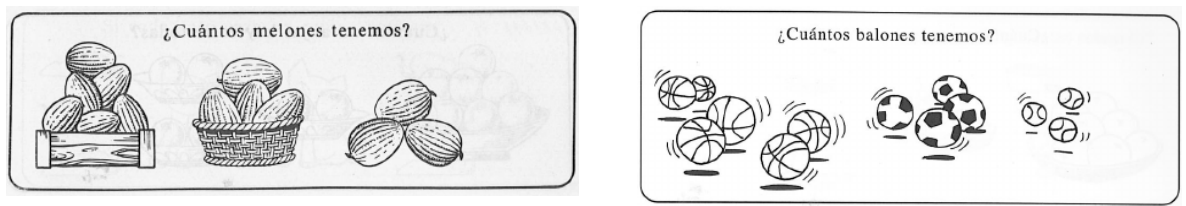

Como ya se ha comentado, en la época 6 se produjo el mayor cambio en estos cuadernos, aunque la mayor parte de los problemas gráficos son los mismos que los de cuadernos anteriores, con distinto diseño, pero los cambios en las cantidades (y, por tanto, en la operación) e, incluso, en el tipo de objetos fueron pocos y no afectaron al tipo de problema (Figura X).

Figura X. El problema Rubio 9.I6.I en la época 2, la época 4 y la época 6, respectivamente.
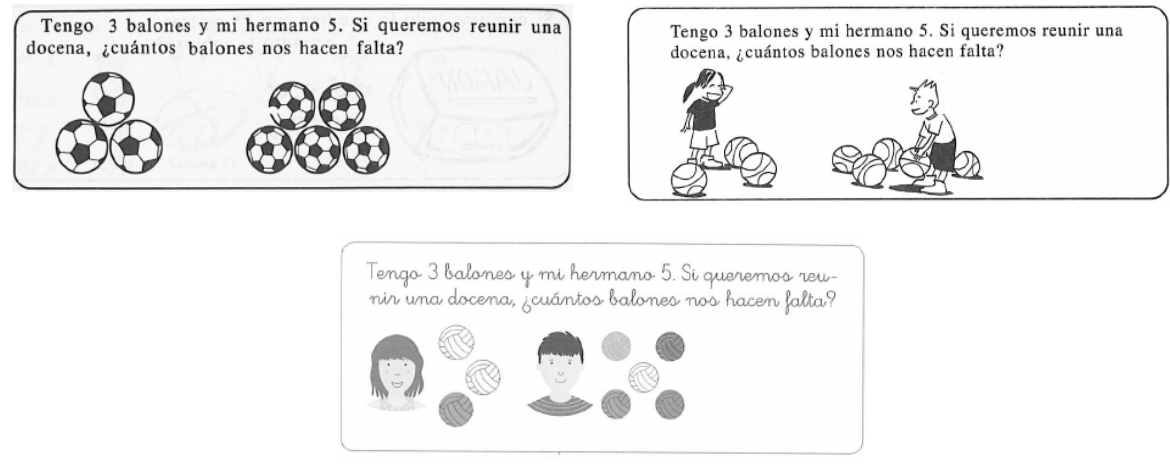

\section{Io. Algunas conclusiones del estudio}

Los cuadernos escolares constituyen una fuente para el estudio de la HEM que ha cobrado importancia en las últimas décadas, ya que muestran parte del trabajo realizado por el alumnado en su aprendizaje. Este trabajo utiliza un tipo de cuadernos escolares, los cuadernos Rubio de aritmética, que se han utilizado 
en España desde 1959 hasta la actualidad. Los cuadernos utilizados pertenecen al fondo de cuadernos escolares del Centro de Estudios sobre la Memoria Educativa de la Universidad de Murcia (CEME). Los cuadernos de aritmética Rubio son del tipo "producidos por casas editoriales», en la clasificación de Viñao (2006); los ejercicios están impresos y con espacios libres para efectuar su resolución, lo que simplifica el trabajo del docente, tanto en la organización de los contenidos como en la forma de proponer el trabajo al alumnado.

A lo largo de los 60 años desde su aparición, los cuadernos Rubio han sufrido variaciones; en este trabajo se identifican seis épocas. Los autores de este trabajo han localizado en papelerías ejemplares desde la época 2, unos en los que se utilizan pesetas y otros con euros, pero la identificación por el comerciante era la misma, el número del cuaderno, sin diferenciar las épocas, pues ha constatado que, en muchos casos, solo ha cambiado la portada. Los cuadernos de la primera edición estaban divididos en «ejercicios», cada uno de los cuales se presentaba como el trabajo que se debía realizar un día laborable, y constaba de operaciones y problemas. A partir de 1978 cambiaron para centrarse en la resolución de problemas, organizados según el ámbito numérico, y las operaciones que se podían utilizar en la resolución.

La estructura de los cuadernos de problemas se mantiene constante de la época 2 a la 5; son cuadernos de 20 páginas y, en general, en cada una de ellas hay un problema planteado de forma gráfica y tres problemas verbales con espacio libre para efectuar la resolución; en la época 6 se quitó un problema verbal de cada página-tipo. Aunque se han tenido en cuenta las edades de utilización sugeridas en los cuadernos a partir de 20I6, hasta ese momento los cuadernos se identificaban por el contenido. Con la realización de los mismos se pretendía afianzar unos contenidos determinados que dependían más de las competencias que había adquirido el alumno que de su edad o nivel educativo, ya que se trata de contenidos asentados en la Educación Primaria, independientes de los planes de estudio, pues siempre figuran en estos. Son un aspecto de la cultura escolar que se ha mantenido estable a lo largo del tiempo.

Se han estudiado los cuadernos editados a partir de 1978, los tres dedicados exclusivamente a las operaciones de sumar y restar (cuadernos 7,8 y 9), que corresponderían a los dos primeros cursos de la Educación Primaria, y los cuadernos I5 y I9, en los que los problemas se resuelven utilizando las cuatro operaciones básicas y que los editores asocian al cuarto curso (el is) y al sexto y último curso de la Educación Primaria (el 19).

Se ha utilizado en el análisis la categorización de los problemas de sumar y restar elaborada por G. Vergnaud en el marco de su teoría de los Campos Conceptuales. De esta manera, se ha podido constatar que en los cuadernos solo aparecen problemas de los tres tipos más sencillos, aquellos en los que intervienen estados, y no hay problemas de los tipos 5 y 6 . Además, en los cinco que se han encontrado de tipo 4, las transformaciones que intervienen pueden reinterpretarse como estados. En las 288 situaciones aditivas analizadas, I66 son de tipo 2 (E-T-E) y, en I27 de ellas la incógnita es el estado final; hay is6 de tipo i (E-E-E), siendo las más 
frecuentes (I27) aquellas en las que se trata de encontrar el estado total; de tipo 3 hay 64 situaciones, la mayoría (53) en las que la incógnita es la comparación, y no hay ninguna en la que se pregunte por el estado I.

En cuanto a los datos de los problemas, las dos terceras partes de las situaciones, aproximadamente, se refieren a cardinales de colecciones y una tercera parte a medida de magnitudes. Las situaciones de medida van aumentando a lo largo de los cuadernos; en los primeros ( 7,8 y 9) las únicas magnitudes que se usan son el dinero (39 situaciones) y la duración (6 situaciones); en los otros cuadernos también hay situaciones de peso (19), longitud (8) y capacidad (5). Uno de los problemas se refiere a posiciones temporales, con significado ordinal.

Hasta 2002 (época 2 y primera subépoca 3) los números que aparecen en los problemas analizados son números naturales; de hecho, solo hay un problema (en el cuaderno in y sin etapa aditiva) que utilice una longitud expresada con un número decimal; el resto de las medidas que aparecen, referidas a cualquier magnitud, son medidas enteras. Sin embargo, en los cuadernos 6 y 6A de esas mismas épocas, dedicados a operaciones aritméticas de «sumar, restar, multiplicar y dividir decimales», hay problemas gráficos en los que los datos son números decimales, y las operaciones que hay en esos mismos cuadernos son mucho más complicadas que las que aparecen en los cuadernos de problemas que, según los editores, se dirigen al mismo nivel. Por tanto, la propuesta parece ser que primero se enseña y se ejercita el algoritmo y, después, se aplica a la resolución de problemas, aunque utilizando números más pequeños y con predominio del significado cardinal. Los números decimales se hicieron necesarios y habituales cuando, en 2002, la unidad monetaria pasó de la peseta al euro. Fue a partir de ese momento cuando se introdujeron los números decimales en los problemas, sobre todo cuando se referían al dinero.

Los problemas gráficos suelen ser problemas verbales en los que alguno de los datos ha sido sustituido por una imagen. Esta funcionalidad de las imágenes es diferente de las que aparecen en los cuadernos de operaciones I, IA, 2, 2A, 3, 3A, 4 y $4 \mathrm{~A}$, pues en estos las ilustraciones plantean un problema sin que intervenga un enunciado verbal y, por tanto, las ilustraciones tienen que presentar tanto los datos como la acción asociada al problema. No es así en los cuadernos analizados en los que imágenes iguales se asocian a problemas de distinto tipo, pues es el enunciado verbal el que realmente plantea el problema.

Los cambios a lo largo del tiempo en los cuadernos Rubio de problemas se han debido, fundamentalmente, al cambio en el sistema monetario en España (2002) y a la modificación de las ilustraciones. Cuando, en 2002, se pasó de la peseta al euro como unidad monetaria, los cuadernos Rubio de problemas se adaptaron a esta nueva situación introduciendo en ellos los mínimos cambios posibles; en muchos casos consistieron en sustituir la palabra «pesetas» por «euros» o por «céntimos» $y$, a veces, con cambios en las cantidades para hacerlas más realistas. Y en los cuadernos más avanzados, como el I5 o el I9, aparecieron problemas con números decimales. 
El cambio en los cuadernos en la época 4 afectó, sobre todo, al diseño. Se cambiaron las ilustraciones, pero también se modernizó la redacción de algunos problemas adecuándola a los valores que, en esos momentos, se consideraba que debían ser transmitidos al alumnado; pero el tipo de problema, los números que intervenían y la operación que lo resolvía era la misma.

En la época 6, el cambio se basó en un nuevo diseño, con ilustraciones en color, pero también con una reducción del $25 \%$ de los problemas planteados por eliminación de problemas verbales, aumentando de esa forma el peso de los problemas gráficos.

El análisis realizado sobre las situaciones aditivas de los cuadernos Rubio se encuadra en un proyecto de estudio de las actividades aritméticas que proponen los cuadernos «producidos por casas editoriales». Dentro de ese proyecto se incluye la comparación con otros cuadernos de este tipo, especialmente con los producidos por editoriales que también comercializan libros de texto.

Anne Marie Chartier comenta que los cuadernos escolares muestran cómo «l'école fait entrer les jeunes générations dans une certaine culture écrite; elle transmet un découpage des savoirs en "disciplines scolaires" définies par des exercices canoniques autant que par des contenus» ${ }^{41}$. Los cuadernos de problemas Rubio recogen un tipo de esos «ejercicios canónicos» que definen la aritmética escolar, su alcance y límites, en la Educación Primaria.

${ }^{41}$ Chartier, A. M. : «Travaux d'élèves et cahiers scolaires: l'Histoire de l'Éducation du côté des pratiques», en Jiménez Eguizábal et al. (coords.): Etnobistoria de la escuela. XII Coloquio Nacional de Historia de la Educación, Burgos, SHEDE y Universidad de Burgos, 2003, pp. 22-40, cita en pp. 23-24. 